\section{Obituary Charles Roberts Schuster}

Neuropsychopharmacology (20I I) 36, 2782; doi: 10.1038/npp.201।.71

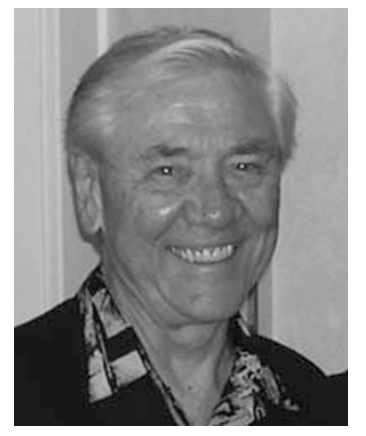

Charles Roberts (Bob) Schuster was born and grew up in New Jersey across the Delaware from Philadelphia. His father was a grocer-butcher, his gracious and delightful mom sang in the choir, and there was never a doubt that Bob revered his older sister. He learned the trumpet early and had great affection for jazz throughout his life. Nothing would portend the dedicated public health administrator that he would become.

He stayed close to home early, starting his college years at Gettysburg College, and then ventured further with early graduate study at the University of New Mexico. He was employed briefly at Smith, Kline, and French in Philadelphia not long after chlorpromazine was introduced to medicine. He then returned to graduate study at the University of Maryland under the supervision of Joseph Brady. During Bob's tenure, Brady and he formed a company using trained animals to advertise products in live public demonstrations. Concurrently, he was becoming a behavioral pharmacologist with a strong interest in primates. At Maryland, he partnered with Travis Thompson on a seminal set of observations in morphine-dependent rhesus monkeys that self-administered morphine intravenously. It was a very ambitious project that was to land him his first academic position.

Following his doctoral thesis, he took a position in the Department of Pharmacology at the University of Michigan, a mecca of preclinical academic opioid research, where Maurice Seevers was Chair. Seevers was at the pinnacle of his career, and Bob had considerable respect and interest in his science-statesmanship. Soon thereafter, having established a very productive laboratory in Pharmacology, he left for a promotion at the University of Chicago, working under Daniel X Freedman and with Jerome Jaffe; they offered him an opportunity to work with addict patients. Bob developed a strong research group embracing pharmacology, psychology, and psychiatry with collaborative relations with a number of colleagues in these disciplines.

His world grew in complexity and richness in Chicago. He married Chris Ellyn Johanson, and they started a family, and they became a fully cooperative and very effective research team. The labs developed and increased their scope. Bob rose through the ranks to chair the Department of Psychiatry briefly before being appointed as Director of the National Institute for Drug Abuse at the NIH for six expansive years. He was a good shepherd, and he loved it. He appreciated the complexities of the problems and how effective administration could help make the problems easier to grasp and deal with; the staff of the Institute could sense his enjoyment. He avoided many pitfalls, and never came to think that he would solve the public's problem. Throughout the rest of his career, he often remarked on the perspective and excitement that the Directorship afforded him.

Following his resignation and a short stay at the NIDA Addiction Research Center in Baltimore, Bob and Chris Ellyn left positions there to take responsibility for forming a drug abuse research center at Wayne State University in Detroit, Michigan. It would have been easy for him to enjoy his laurels, but he started anew and was, of course, very successful in establishing a unit that specialized in human drug abuse research along with excellent clinical care. They then returned to Chicago, the city for which they had developed enormous affection, to take positions at Loyola at its Institute for Neuroscience, where Bob was Head until their retirements last year.

Even afterward, Bob continued an active role in professional societies; he was always ready to contribute his time and effort to support his devotion to the activities of the sciences he loved. He and Chris Ellyn were vacationing in San Miguel, Mexico when he had a stroke; they returned to Houston for medical care from their family. He did not recover and died on 21 February 2011.

Bob is survived by four children, Rebecca, Liz, Rob, and Alyson, and a batch of loving grandchildren.

Jack Bergman ${ }^{1}$ and James $\mathrm{H}$ Woods ${ }^{2}$

${ }^{1}$ McLean Hospital/Harvard Medical School, Preclinical Pharmacology, Belmont, MA, USA;

${ }^{2}$ Department of Pharmacology, University of Michigan Medical School, Ann Arbor, MI, USA E-mail: jack_Bergman@hms.harvard.edu 